\title{
Habitat degradation threatens the survival of the Ethiopian bush crow Zavattariornis stresemanni
}

\author{
Luca Borghesio and Fabio Giannetti
}

\begin{abstract}
The Ethiopian bush crow Zavattariornis stresemanni is one of the most remarkable ornithological discoveries of the 20th century. It is restricted to an area of $c .5,000 \mathrm{~km}^{2}$ in southern Ethiopia, and a large part of its range is protected inside Yabello Wildlife Sanctuary. We report on the results of roadside counts carried out in 1989, 1995 and 2003 showing that the population of the species has decreased by $80 \%$ during this time. By comparing two Landsat satellite images from 1986 and 2002, we highlight land cover trends within the range of the species. These include a general increase in bush density, probably related to increasing grazing pressure by domestic animals, fire suppression (only in the Sanctuary) and the disappearance of wild herbivores. Land cover trends differed between the Sanctuary and
\end{abstract}

the area outside, where open areas expanded, apparently indicating an increase in agricultural exploitation. Satellite images also showed that, within its range, the bush crow selects areas having relatively open terrain. Our data suggest that the population decrease within the Sanctuary could be due to the encroachment of open savannah by dense bush and that, therefore, the Sanctuary has failed to protect the bush crow. More research is urgently needed to evaluate its conservation status outside the Sanctuary and the impact of human activities on the species.

Keywords Conservation status, Ethiopian bush crow, habitat change, Landsat, remote sensing, Zavattariornis stresemanni.

\section{Introduction}

The Ethiopian bush crow Zavattariornis stresemanni, endemic to south Ethiopia, is probably one of the most remarkable ornithological discoveries of the 20th century in Africa (Collar \& Stuart, 1985). Its taxonomic position is uncertain, and it has been classified in Corvidae, Sturnidae, and even its own family (Lowe, 1949; Ripley, 1955; Fry \& Keith, 2000). It remains taxonomically enigmatic, and its restricted range, which does not apparently relate to any clear habitat discontinuity (Collar \& Stuart, 1985), makes it a species of special interest.

Field data on the Ethiopian bush crow are scarce, and many aspects of its biology are almost unknown (Fry \& Keith, 2000). It ranges over an area of $c .5,000 \mathrm{~km}^{2}$ around the towns of Yabello and Mega in south Ethiopia, where it lives in open, park-like, short-grass savannah with scattered trees (Dellelegn, 1993; BirdLife International, 2000). A large part of its range is included in Yabello Wildlife Sanctuary, which has not yet been gazetted and that receives little or no official protection. The

Luca Borghesio (Corresponding author) C. Re Umberto 42, I-10128, Torino, Italy. E-mail borghesio@libero.it

Fabio Giannetti IPLA, C. Casale 476, I-10132, Torino, Italy.

Received 8 January 2004. Revision requested 4 June 2004. Accepted 12 August 2004. population has been estimated at $>10,000$ individuals, thought to be slightly decreasing, and the species is believed to be able to tolerate a substantial amount of human activity in its habitat (BirdLife International, 2000), although there are contrasting opinions on this (Ash \& Gullick, 1989; Hundessa, 1991; Syvertsen \& Dellelegn, 1991).

The Ethiopian bush crow is categorized as Vulnerable on the IUCN Red List (IUCN, 2003). However, habitat alteration within its restricted range, due to cattle- and goat-breeding as well as agricultural expansion, may now be having a detrimental effect on its population (Bassi, 2003).

Here we provide evidence, based on road counts carried out between 1989 and 2003, that the population is rapidly decreasing, and relate this to land cover changes by analysing satellite images from 1986 and 2002. This new information suggests that this enigmatic species is now in need of urgent conservation action due to deteriorating habitat quality.

\section{Study area}

The study area (Fig. 1a) was determined by mapping all the available distribution records of the Ethiopian bush crow, including data collected by us during two visits to the area in March-June 1995 and February 2003, and information extracted from the BirdLife database 

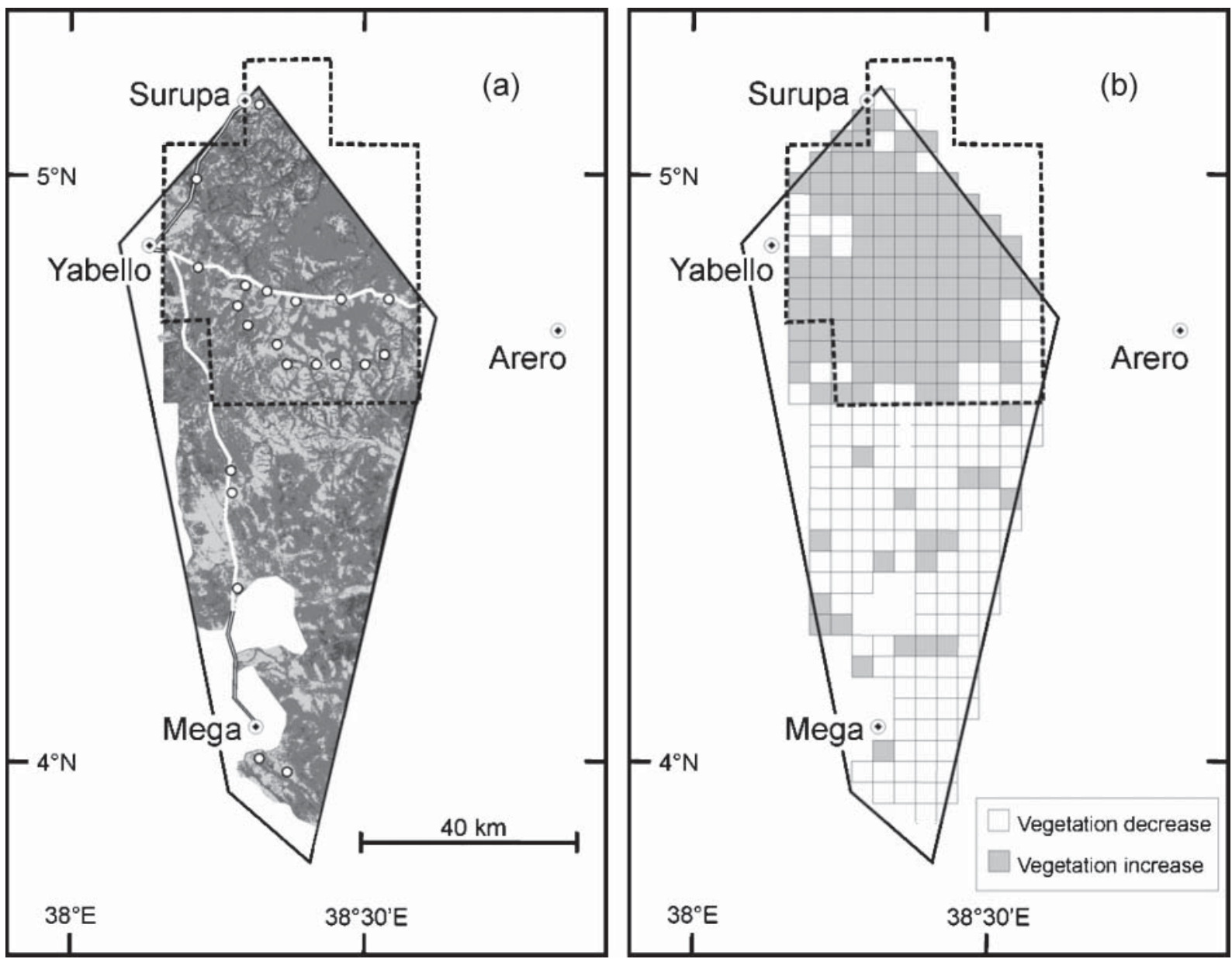

Fig. 1 (a) Map of the survey area, showing the approximate range of the Ethiopian bush crow (continuous line), the borders of Yabello Wildlife Sanctuary (broken line), the three roads where counts were done (white lines), the 21 points used in the analysis of large-scale habitat selection, and the distribution of the three habitat types in February 2002 (light grey, open terrain; medium grey, dense bush; dark grey, woodland). The white areas within the crow's range are habitat types not used by the bush crow. (b) Vegetation changes within the range of the Ethiopian bush crow, 1986-2002. In grey squares there was a general increase of vegetation thickness, whereas in open squares there was a decrease.

(BirdLife International, 2000). The resulting convex polygon encompasses an area of $4,890 \mathrm{~km}^{2}$.

The study area comprises most of Yabello Wildlife Sanctuary and its immediate surroundings, south to the town of Mega, with a general altitude range of 1,300$1,800 \mathrm{~m}$. Rainfall is c. $700 \mathrm{~mm}$ per year and mean annual temperature $19^{\circ} \mathrm{C}$ (EWNHS, 1996). A few montane areas have altitudes of $>2,000 \mathrm{~m}$, but are covered with forests of Juniperus procera, which is not a bush crow habitat. The most common habitat is a woodland savannah dominated by species of Acacia (A. tortilis, A. brevispica, A. horrida, A. drepanolobium), Terminalia (especially $T$. brownii) and Commiphora. The dominant land use is traditional nomadic pastoralism as practised by the local Borena tribe (EWNHS, 1996). However, agriculture has increased in recent years (Bassi, 2002, 2003). The study area has a high biological value, as it comprises not only the range of the Ethiopian bush crow, but also a substantial part of that of the white-tailed swallow Hirundo megaensis, another restricted-range, Vulnerable Ethiopian endemic (Collar \& Stuart, 1985; Hillman, 1993; BirdLife International, 2000).

\section{Methods}

We visited the study area twice, in 1995 (29 March and 3-7 June) and over 12-24 February 2003. On each visit, roadside counts were conducted along a $60 \mathrm{~km}$ section of the Arero-Yabello road, the $38 \mathrm{~km}$ Yabello-Surupa road and (only in 1995) the $97 \mathrm{~km}$ between Yabello and Mega (Fig. 1a). During each count a vehicle was driven at constant $\left(40 \mathrm{~km} \mathrm{hr}^{-1}\right)$ speed and the same observer (LB) counted all the birds along both sides of the road. We also included in the analysis the data published by Hundessa 
(1991), who adopted a similar count technique along the same roads in 1989-90.

We evaluated land cover changes in the study area by comparing two Landsat satellite images (January 1986 and February 2002). Images were resampled to a pixel dimension of $28.5 \mathrm{~m}$, overlain on 1:50,000 maps produced by the Ethiopian Mapping Authority, and checked with a global positioning system (GPS) in the field. The spatial precision of the images was approximately one pixel with respect to maps and field measurements. Images were displayed in multispectral combination of bands 4-5-3 and visually interpreted based on habitat descriptions recorded in 96 locations recorded with a GPS in and around the survey area over 12-21 February 2003. In both sets of images we distinguished three land cover types: woodland (with tall trees, mostly along temporary watercourses and in areas with wetter soils), dense bush (scattered trees within a dense bush cover 1-3 m high), and open terrain (scattered trees, but with discontinuous bush cover and wide expanses of grass; cultivated areas were also lumped within this habitat category as they could not be reliably distinguished from natural habitats in satellite images). Some habitat types (Juniperus procera forests, rocky areas, salt pans) that are not used by the bush crow were not considered in the land-cover change analysis. Areas within and outside Yabello Wildlife Sanctuary were analysed separately.

To assess the effects of the Sanctuary on land cover changes between 1986 and 2002 we superimposed a grid of $4^{*} 4 \mathrm{~km}$ over the study area. We then counted within each tile all the pixels that changed from one land cover type to another between 1986 and 2002. Each pixel was scored positively if it changed to a land cover type with thicker vegetation (i.e. from open terrain to dense bush or woodland, or from dense bush to woodland), and negatively if the reverse was true. A total score (the sum of the scores of all pixels) was then calculated for each tile.
We evaluated large-scale habitat selection by the Ethiopian bush crow using an analysis of the spatial distribution of the records of its presence. We selected the 21 records that were within the area of the satellitederived habitat map, and calculated the amount of the three habitat types within a $2 \mathrm{~km}$ radius around each point. This fairly wide radius seemed appropriate as all the records for before 2003 had been plotted on the map manually, without the use of a GPS. We then used a one-way ANOVA on log-transformed data to compare the plots where bush crow presence had been confirmed with an equal sized sample of non-overlapping $2 \mathrm{~km}$ radius areas located randomly within the species' range. We performed the analysis separately for 1986 and 2002 land cover data to test if our results were consistent across time.

\section{Results}

Counts carried out between 1989 and 2003 suggest that the population of Ethiopian bush crows is steadily decreasing (Fig. 2). The average number of sightings per $\mathrm{km}$ decreased by $80 \%$ from $1.3 \pm$ SD 0.8 to $0.3 \pm 0.1$. Although there was considerable variation in the average sighting frequency, the decreasing trend was consistent across the three stretches of road (Fig. 2). Counts carried out along the Yabello-Arero road, in the Yabello Wildlife Sanctuary, were higher than those of other roads (ANOVA on log-transformed data: $F_{1,9}=13.4, \mathrm{P}<0.01$; Fig. 2).

Comparison of random points with plots where the species presence had been confirmed suggested that, within its range, the species selects areas with more open terrain, and less woodland and dense bush. Results were qualitatively similar both in 1986 and 2002 (Table 1).

The relative proportions of the three habitat types inside and outside the Sanctuary were similar. In both years dense bush was the most widespread habitat,

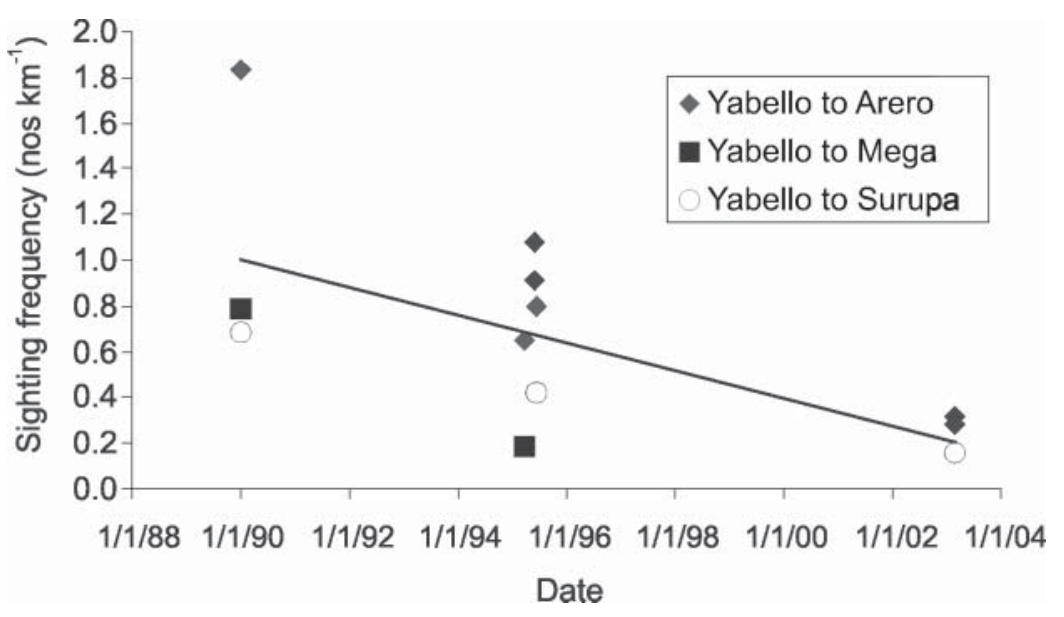

Fig. 2 Sighting frequency (numbers $\mathrm{km}^{-1}$ ) of Ethiopian bush crow in roadside counts from 1989 to 2003. Regression line equation is $y=-1.7^{*} 10^{-4} x+6.8\left(R^{2}=0.43 ; \mathrm{P}=0.02\right)$. 
Table 1 Area occupied by three land cover types in $212 \mathrm{~km}$-radius plots where Ethiopian bush crow presence was confirmed and in 21 equal-sized, randomly selected plots within the known range of the species, both in 1986 and in 2002. Differences were tested with a one-way ANOVA on log-transformed data.

\begin{tabular}{|c|c|c|c|c|}
\hline \multirow[b]{2}{*}{ Land cover type } & \multicolumn{2}{|l|}{ Area (ha) } & \multirow[b]{2}{*}{$F_{1,40}$} & \multirow[b]{2}{*}{$\mathrm{P}$} \\
\hline & Random plots & Bush crow plots & & \\
\hline \multicolumn{5}{|l|}{1986} \\
\hline Woodland & 144 & 79 & 6.70 & 0.01 \\
\hline Dense bush & 753 & 637 & 2.49 & 0.12 \\
\hline $\begin{array}{l}\text { Open terrain } \\
2002\end{array}$ & 352 & 530 & 4.91 & 0.03 \\
\hline Woodland & 118 & 85 & 0.15 & 0.70 \\
\hline Dense bush & 813 & 667 & 4.02 & 0.05 \\
\hline Open terrain & 317 & 494 & 5.59 & 0.02 \\
\hline
\end{tabular}

(a) Outside the Wildlife Sanctuary

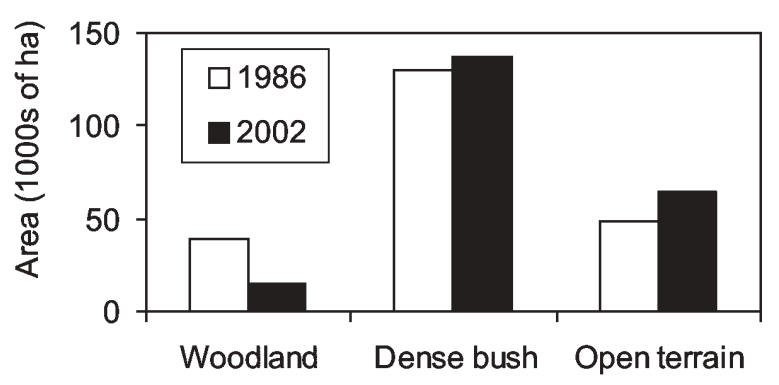

(b) Inside the Wildlife Sanctuary

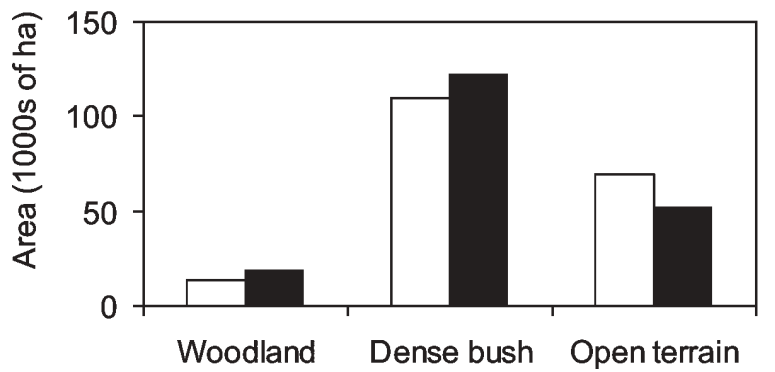

Fig. 3 Areas of land cover types outside (a) and inside (b) the Yabello Wildlife Sanctuary in 1986 and 2002.

followed by open terrain and woodland (Fig. 3). Considering the whole of the area, woodland decreased by $34 \%$, dense bush increased by $8 \%$, and open terrain decreased by $2 \%$. However, patterns of land cover change differed in different parts of the study area: outside the Sanctuary, woodland area decreased by $61 \%$ and open terrain increased by 33\% (Figure 3a). By contrast, inside the Sanctuary woodland increased by $46 \%$ and open terrain decreased by $26 \%$ (Figure 3b). Dense bush increased by $11 \%$ within the Sanctuary and by $6 \%$ outside.
Land cover changes between 1986 and 2002 showed a clear non-random spatial structuring: most squares inside the Sanctuary showed an increase in vegetation thickness, whereas the opposite was true outside the Sanctuary (Fig. 1b; Chi-squared test, $\mathrm{df}=1, \mathrm{P}<0.001$ ).

\section{Discussion}

Our analysis suggests that the conservation status of the Ethiopian bush crow should be reconsidered, as it seems to be seriously threatened by habitat deterioration within its restricted range. Our data provide the first quantitative assessment of the population and habitat selection of the Ethiopian bush crow and, taken together with the survey data of Hundessa (1991) along the same stretches of road, suggest that between 1989 and 2003 bush crow numbers decreased by c. $80 \%$. Our data also confirm that, as originally suggested by Syvertsen \& Dellelegn (1991), the nucleus of the species' range is along the YabelloArero road in the southern part of the Yabello Wildlife Sanctuary. The area within the Sanctuary is therefore of primary importance for conservation of the bush crow. There have also been other earlier roadside counts of the Ethiopian bush crow (Ash \& Gullick, 1989; Syvertsen \& Dellelegn, 1991), but these could not be compared with our data as both census techniques and survey areas differed.

Dunn (2002) warned against identifying species at risk on the basis of numerical estimates alone, because natural populations can be subject to large temporary fluctuations through natural causes such as climate variability, and short-term numerical decreases can be reversed over longer time frames. However, in the case of the Ethiopian bush crow, our data spans 14 years, and we also found evidence of widespread habitat changes that could have triggered a permanent population reduction. The analysis of satellite imagery showed that between 1986 and 2002 there were marked changes in the distribution of land cover types in the study area. Within the Sanctuary there was a widespread increase in vegetation thickness, whereas the opposite was true outside the Sanctuary. Thus, the creation of the Sanctuary, in 1978, caused a noticeable change in the distribution of the different habitat types during the time frame considered.

We found that the bush crow was more likely to occur in areas of relatively open terrain, and its decrease may therefore be linked to the contraction of that habitat. The increase in open areas outside the Sanctuary could represent an increase in habitat quality for the species, but could also be the result of agricultural expansion, a process that has been underway in the area since the 1980s (Ash \& Gullick, 1989), and the effects of which on the species are unknown. Recent information (Bassi, 2003) suggests that in the surroundings of Mega (outside 
the Sanctuary), bush crow populations have greatly decreased as a consequence of expanding cultivation. It is thus possible that bush crows outside the Sanctuary may be decreasing, but this needs to be tested by further fieldwork.

The first and most widespread factor in land use change within the range of the bush crow seems to be an intensification of grazing by domestic animals. This is suggested by the increase of dense bush in all of the study area. An expansion of bushland, dominated by unpalatable thorny shrubs, is a common feature of overgrazed pastures in Africa (Pratt \& Gwynne, 1977; Tobler, et al., 2002; Riginos \& Hoffman, 2003). Similar effects have also been reported at Arero, c. $30 \mathrm{~km}$ east of the study area (Borghesio et al., 2004), and are also likely to occur within the bush crow range, especially in the Sanctuary which, besides being a wildlife protection area, coincides with a large government-owned ranch (Hillman, 1993). Another factor that might have triggered the increase of shrubland is the almost complete disappearance of large herbivores (African elephant Loxodonta africana, giraffe Giraffa camelopardalis and African buffalo Syncerus caffer), whose browsing is known to favour more open, grassland savannah habitats (Laws, 1970; Gichohi et al., 1996).

Contrary to dense bush, woodland habitat decreased markedly, but trends were opposite inside and outside the Sanctuary. Felling of trees by local people was reported by Dellelegn (1993) and Bassi (2003) but seems to have been less intensive inside the Sanctuary, perhaps as a consequence of better law enforcement. We also hypothesize that an important role was played by fire suppression. The government-owned ranch has created an extensive network of fire bridges that are visible even in satellite images. Fire suppression might have stimulated the growth of trees and shrubs in the Sanctuary.

In summary the population of the Ethiopian bush crow appears to have decreased by c. $80 \%$ in the area thought to include the nucleus of its range, and there has been a general decrease of habitat quality in the Yabello Wildlife Sanctuary. Moreover, the creation of a protected area has not had positive effects on the conservation status of the species. We suggest that the Ethiopian bush crow should now be re-categorized as Endangered on the basis of IUCN criteria $\mathrm{A} 2 \mathrm{~b}+\mathrm{c}$ (population decrease of $\geq 50 \%$ inferred over the last 10 years by change in an index of abundance and reduction of habitat quality; IUCN, 2001).

We suggest that future surveys should focus on the areas outside the Sanctuary, to estimate their importance for the Ethiopian bush crow and the impact of agricultural intensification on the species. Another important issue is the possible use of prescribed fire to check the expansion of dense bush; this could be a cheap and effective way to improve habitat quality for the species. Immediate action needs to be taken in order to reduce overgrazing and the expansion of bushy vegetation in the area.

\section{Acknowledgements}

This survey was entirely funded by Al Wabra Wildlife Preservation, Sheikh Saoud Bin Mohammad Bin Ali Al-Thani (Qatar), whose support we gratefully acknowledge. We thank Tesfaye Hundessa (Ethiopian Wildlife Conservation Organization), Alemayehu Erena (Oromya Region Rural Land \& Natural Resources Authority) and Kinfe Abebe (Ethiopian Wildlife and Natural History Society) for helping us in obtaining research permits and organizing the survey. Many thanks also to Akale Yemane for his help and to Andrea Borghesio, Aman Dadessa, Ketema Fufa, Omega Girmay, Daniele Rizzo, Anteneh Shimelis, to our drivers and the local guides who participated in the fieldwork. Without their help this survey could never have been accomplished. Sue Shutes of BirdLife International provided access to the BirdLife database. Simon Jensen and Sven Hammer of Al Wabra Wildlife Preservation provided invaluable support and assistance throughout all stages of the project.

\section{References}

Ash, J.S. \& Gullick, T.M. (1989) The present situation regarding the endemic breeding birds of Ethiopia. Scopus, 13, 90-96.

Bassi, M. (2002) Enhancing Equity in the Relationship Between Protected Areas and Local Communities in the Context of Global Change. Horn of Africa and Kenya. Http: / / www.iucn.org/ themes/ceesp/Publications/TILCEPA/CCA-MBassi.pdf [accessed 14 August 2003].

Bassi, M. (2003) The making of unsustainable livelihoods. An ongoing tragedy in the Ethiopian drylands. Policy Matters, 10, 7-12.

BirdLife International (2000) Threatened Birds of the World. Lynx Edicions and BirdLife International, Barcelona, Spain and Cambridge, UK.

Borghesio, L., Giannetti, F., Ndang'ang'a, P. \& Shimelis, A. (2004) The present conservation status of Juniperus forests in the South Ethiopian Endemic Bird Area. African Journal of Ecology, 42, 137-143.

Collar, N. \& Stuart, S. (1985) Threatened Birds of Africa and Related Islands. The ICBP/IUCN Red Data Book. Part 1.3rd edition. ICBP, Cambridge, UK.

Dellelegn, Y. (1993) Observations on the Ethiopian bush crow Zavattariornis stresemanni in Yabello, southern Ethiopia. In Proceedings of the VIII Pan-African Ornithological Congress (ed. R.T. Wilson), pp. 469-474. Musée Royal de l'Afrique centrale, Bujumbura, Burundi.

Dunn, E. (2002) Using decline in bird populations to identify needs in conservation action. Conservation Biology, 16, 1632-1637.

EWNHS (1996) Important Bird Areas of Ethiopia. Ethiopian Wildlife and Natural History Society, Addis Ababa, Ethiopia. 
Fry, C.H. \& Keith, S. (2000) The Birds of Africa. Volume 6. Academic Press, London, UK.

Gichohi, H., Gakahu, C. \& Mwangi, E. (1996) Savanna ecosystems. In East African Ecosystems and their Conservation (eds T.R. McClanahan \& T.P. Young), pp. 272-298. Oxford University Press, Oxford, UK.

Hillman, J.C. (1993) Compendium of Wildlife Conservation. Volume 2: Information on Wildlife Conservation Areas. The Wildlife Conservation Society, New York, USA and Ethiopian Wildlife Conservation Organization, Addis Ababa, Ethiopia.

Hundessa, T. (1991) Survival status review of the Ethiopian bush crow (Zavattariornis stresemanni Moltoni, 1938) in the Borana area, Ethiopia. Walia, 13, 9-13.

IUCN (2001) IUCN Red List Categories and Criteria, Version 3.1. IUCN, Gland, Switzerland and Cambridge, UK.

IUCN (2003) 2003 IUCN Red List of Threatened Species. IUCN, Gland, Switzerland [http:/ / www.redlist.org, accessed 25 June 2004].

Laws, R.M. (1970) Elephants as agents of habitat and landscape change in east Africa. Oikos, 21, 1-15.

Lowe, P.R. (1949) On the position of the genus Zavattariornis. Ibis, 91, 102-104.

Pratt, D.J. \& Gwynne, M.D. (1977) Rangeland Management and Ecology in East Africa. Hodder and Stoughton, London, UK.

Riginos, C. \& Hoffman, M.T. (2003) Changes in population biology of two succulent shrubs along a grazing gradient. Journal of Applied Ecology, 40, 615-625.
Ripley, S.D. (1955) Anatomical notes on Zavattariornis. Ibis, 97, 142-145.

Syvertsen, P.O. \& Dellelegn, Y. (1991) The status of some bird species endemic to south Ethiopia. Scopus, 15, 30-34.

Tobler, M.W., Cochard, R. \& Edwards, P.J. (2002) The impact of cattle ranching on large-scale vegetation patterns in a coastal savanna in Tanzania. Journal of Applied Ecology, 40, 430-444.

\section{Biographical sketches}

Luca Borghesio has been studying birds, plants and insects in Italy and east Africa for more than 10 years. His research interests are now mainly focused on the ecology and biogeography of bird and plant communities in a group of isolated forests in northern Kenya. He is also applying research data to the management and planning of protected areas in north-western Italy.

Fabio Giannetti specializes in the analysis of remote sensing data. He is using satellite and aerial images to elaborate habitat maps that are used in conservation planning and habitat management of protected areas in northern Italy. He is also exploring the possibility of using remotely-sensed images for studying habitat changes in remote areas of tropical Africa. 